\title{
البــوث والدراسات
}

\section{السياسة الهندية نهو رابطة بيسمستيك (توجه نهو الاقليسيمية)}

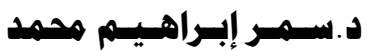 \\ هدير تثرير دورية آناق آسيوية}

مقدهة:

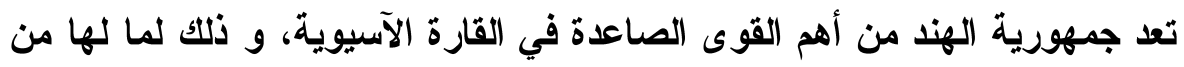

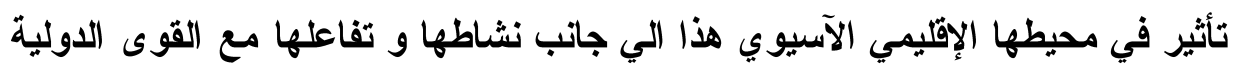

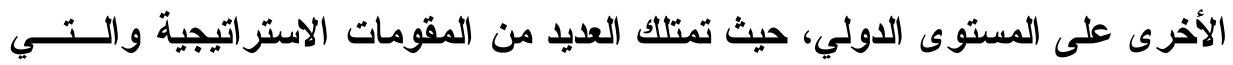

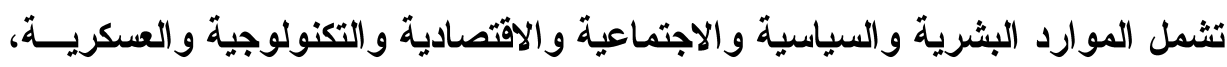

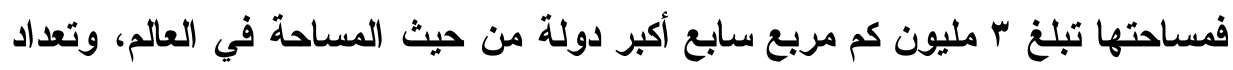

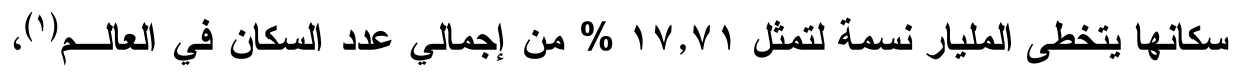

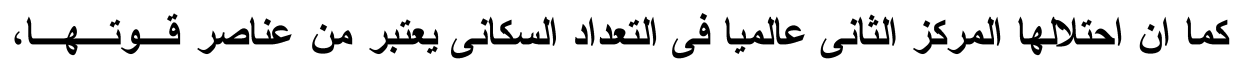

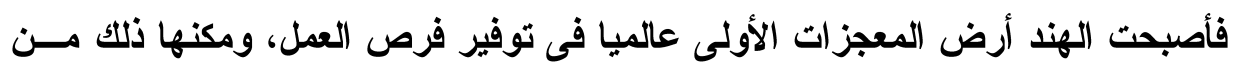
تحقيق نهضنها الاقتصادية.

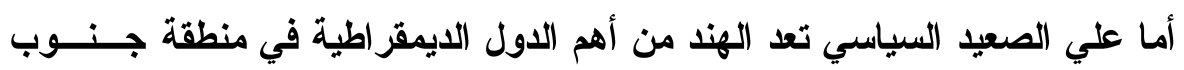

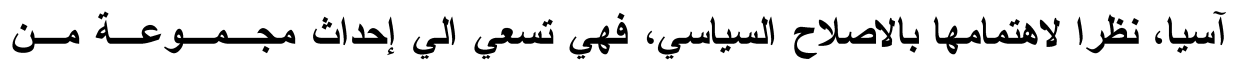

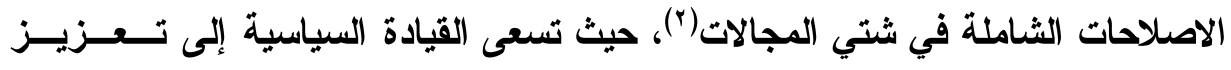

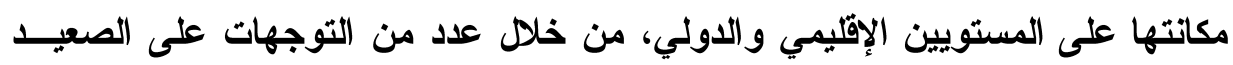

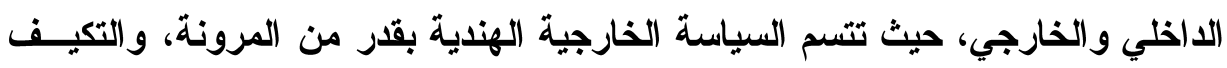

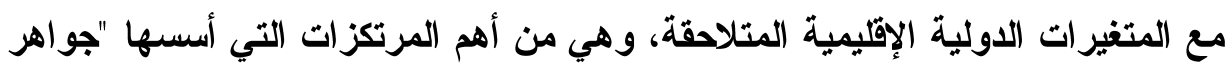

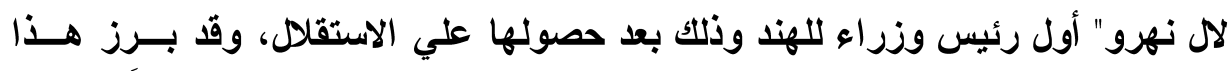

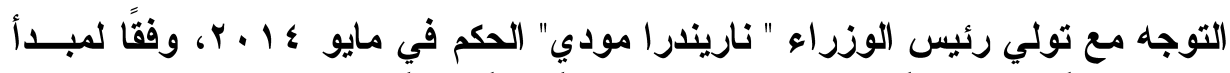

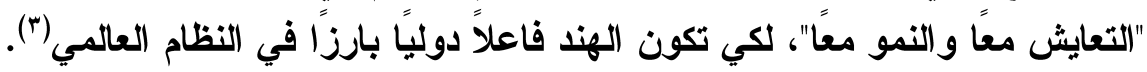




\section{(6)}

ولهذا ستتناول الاراسة تطورونمو القوة الاقتصادية للهند وسياستها لتدعـبــ

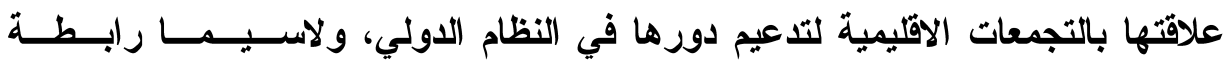

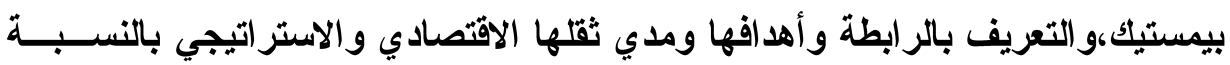

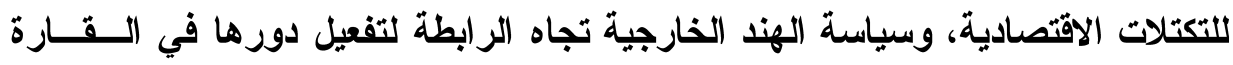
الآسيوية، والتحديات التي تواجهها، وهذا يتضح فيما يلي:

\section{أولا النسمو الاقتصادى للهند :}

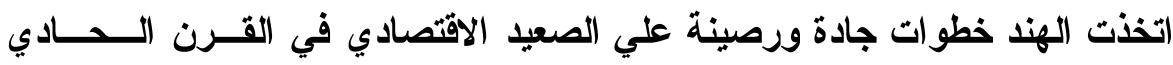
والعشرين لمواكبة التحديّات المختلفة، فقد أكد تقريز مركــز " World Population Review ببريطانيا أن الهند برزت كخامس أقوى اقتصاد في العالم متجاوزة بريطانيا

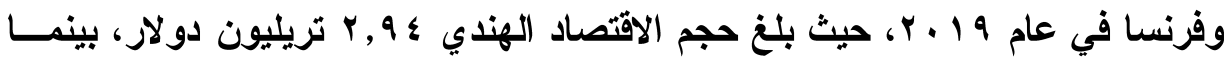

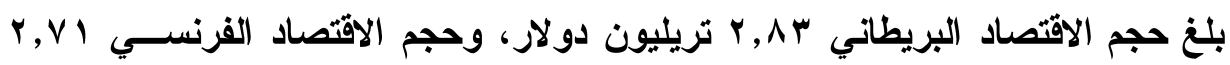
تريليون دولار .

حيث اتبعت الهند سياسات تحرير الاقتصاد والاصلاح الاقتصادي منذ تسعيـــــــــات

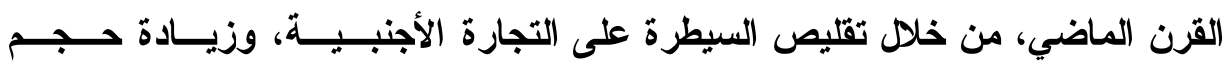

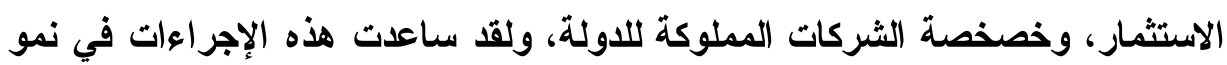

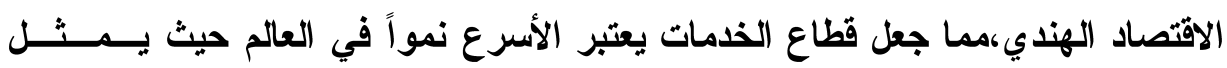

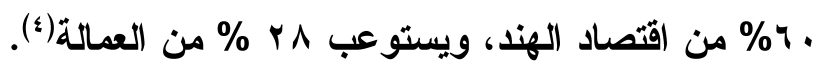
و لهذا شهر الناتج المحلي الاجمالي للهند العديد من التغيرات اتوعن المختلفة ولا سيما أنه

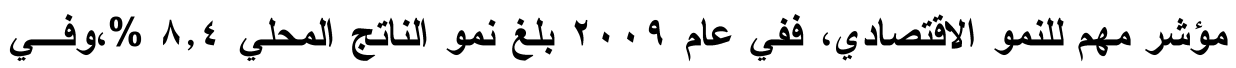

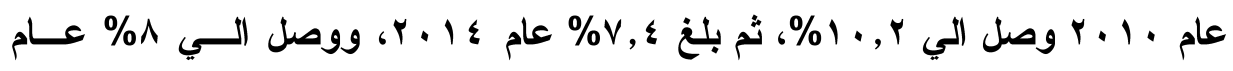

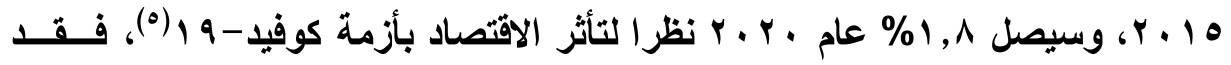

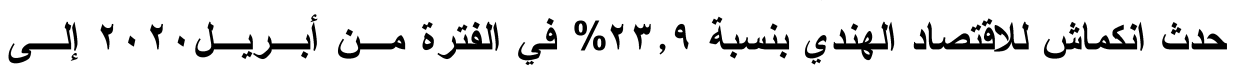

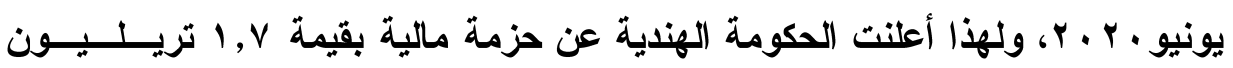

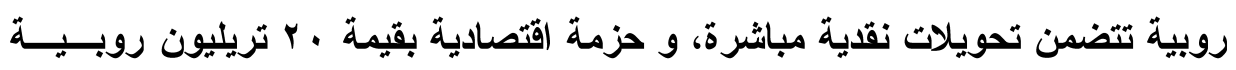

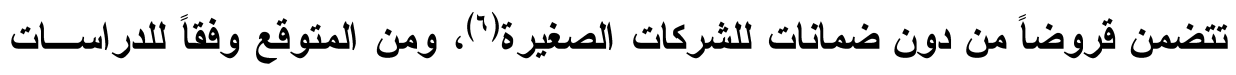




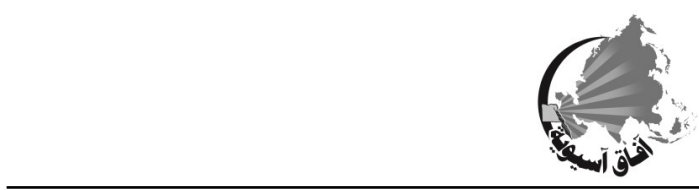

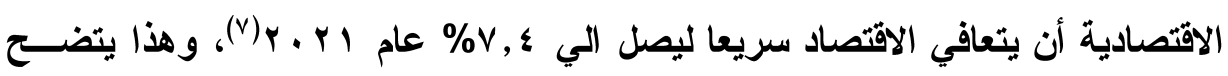
في الثكل البياني التالي :

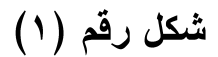

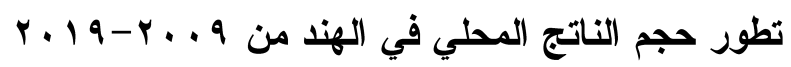

India: Real gross domestic product (GDP) growth rate from 2009 to 2021 (compared to the previous year)

\section{$12.5 \%$}

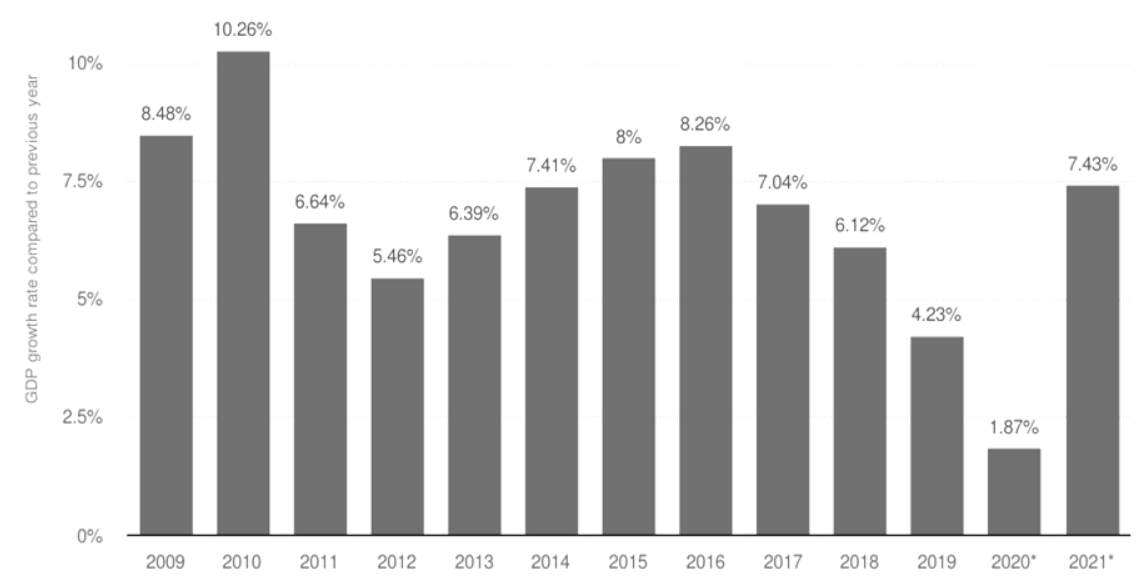

Source

IMF
Statista 2020

ونظراً لقدرة الاقتصاد الهندي علي مواجهة التغيرات والظروف الاقتصادية الطارئة،

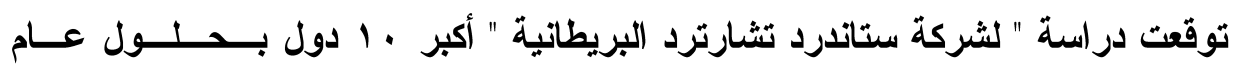

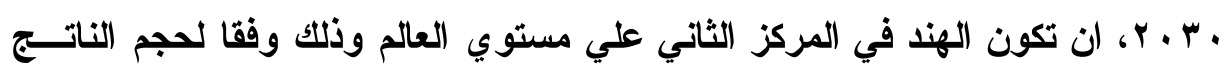
المحلي الاجمالي، وهذا يتضح في الشكل التالي : 


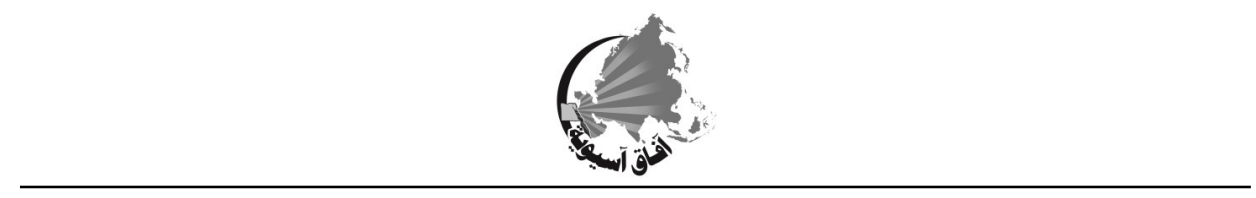

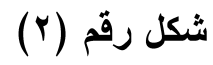

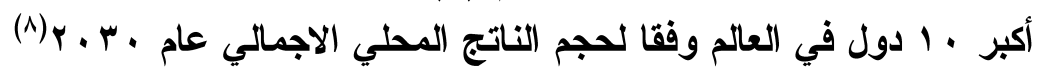

\section{Rising Stars?}

Top 10 countries by nominal GDP using PPP exchange rates by the year 2030

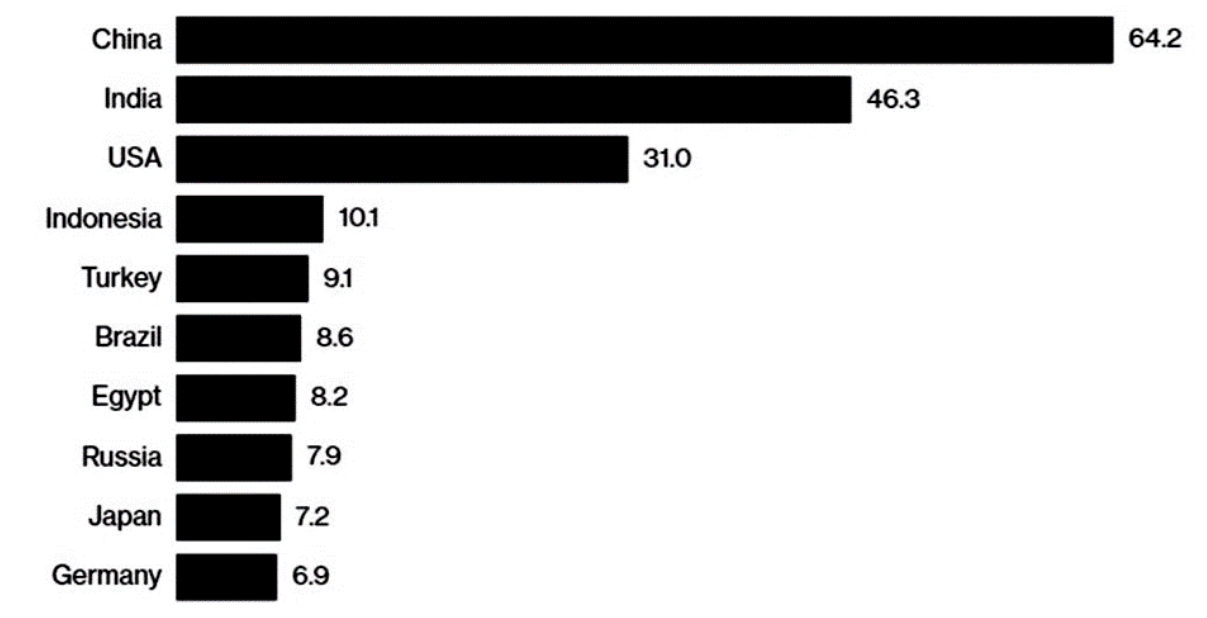

Source: Standard Chartered

Note: Estimates are in trillions of international dollars, using purchasing power parity measures

ووفقاً للارسة من المتوقع أن تصبح الصبين أكبر اقتصاد حول العالم وستتـجـــاوز

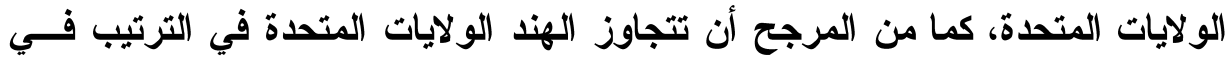

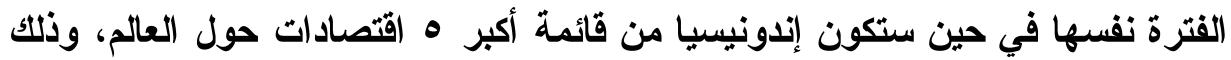

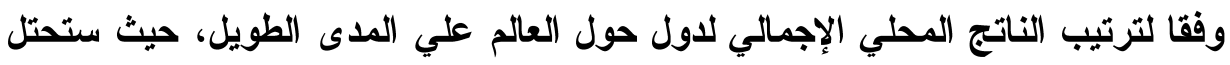

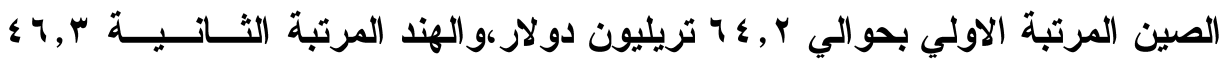

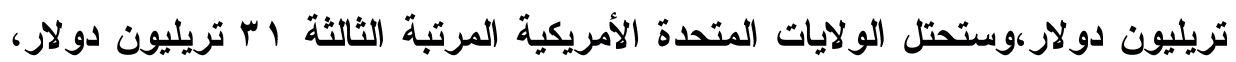

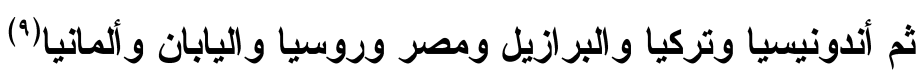

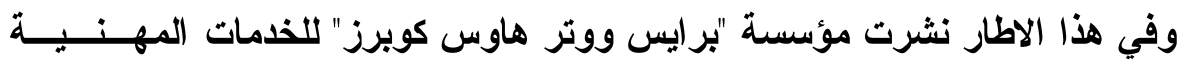

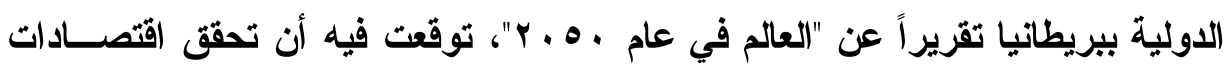

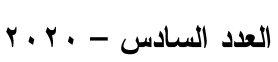
$11 Y$ 


\section{敦}

الأسواق الصاعدة الكبرى نمواً بوتيرة أسرع مرتين مقارنة بالاقتصادات المتقدمة، ومن

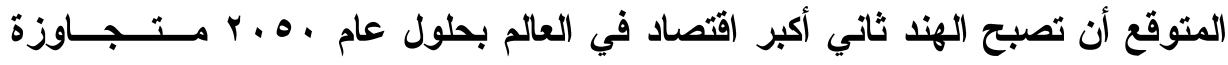
الولايات المتحدة، حيث سترتفع حصة الهند في الناتج الإجمالي العالمي إلـى هـ 1 \% وستشهد نمواً بمعدل ه \% سنويا في الناتج المحلي الإجمالي، لتصبح واحدة من أسرع الاقتصادات نموا في العالم (·').

\section{ثانيا السياسة الخارجية الهندية:}

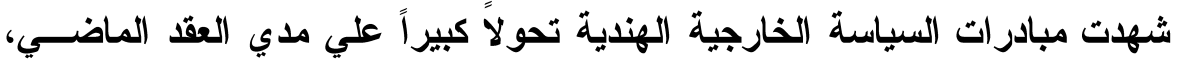

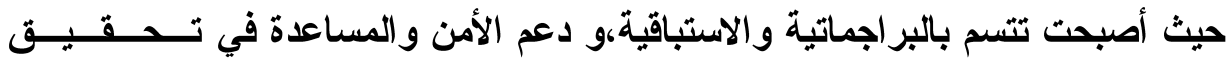

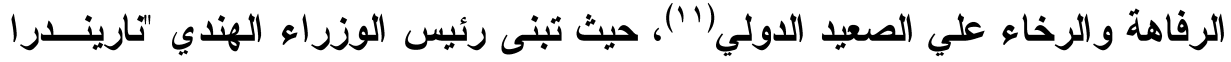

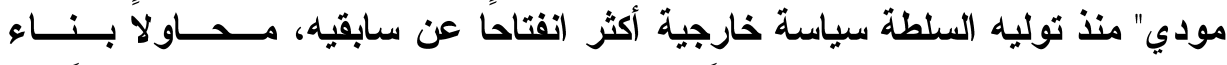

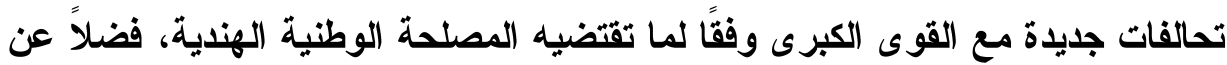

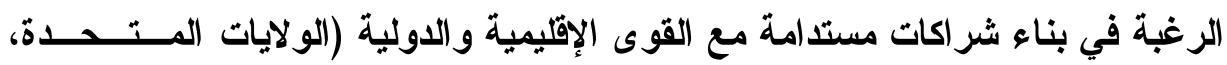

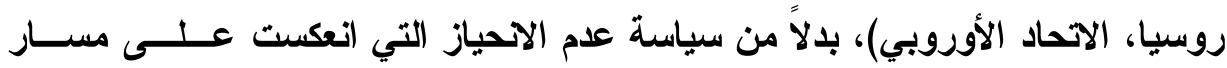

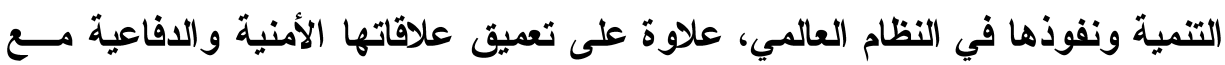
جميع القوى الدولية"(ri). ومنذ فوز "تاريندرا مودي" رئيس الوزراء الهندي وزعيم الحزب الحاكم "بهاراتيــا

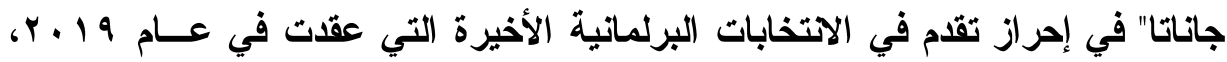

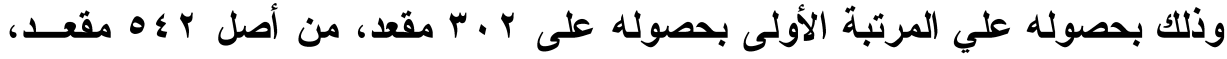

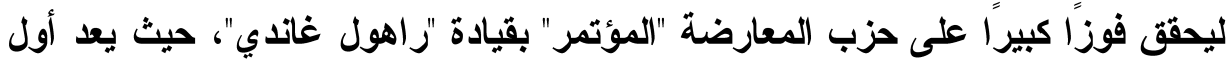

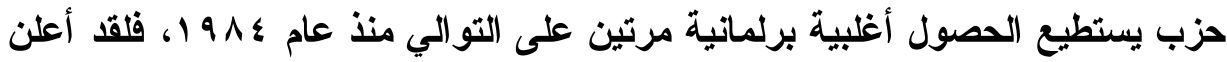

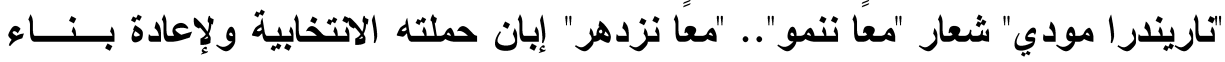

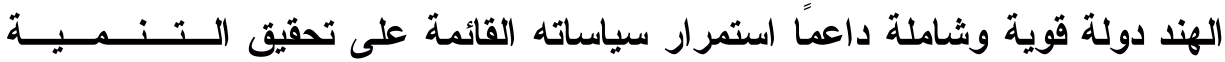

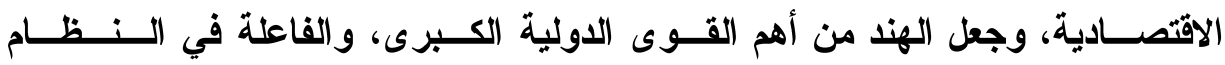

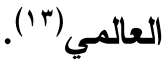

ولهذا اتخذت الدبلوماسية الهندية شعاراً جديدا من أجل تحقيق التنمية، من خــلال الوصول بحجم الاقتصاد الهندي الي ه تريليون دولار، وتم توجيه السياسة الخارجيـة

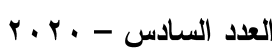




\section{6}

الهندية للاستفادة من شبكة الشر اكات التي تم ارسائها مع دول العالم من أجل تحقبـق

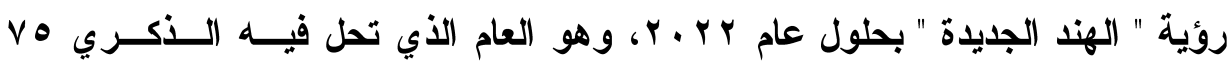

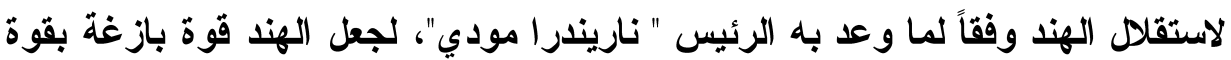

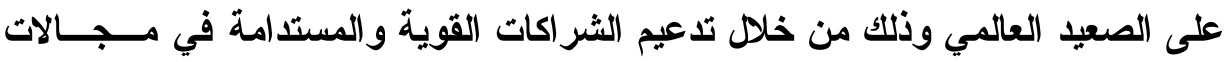

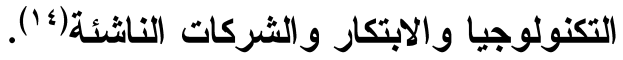

ومن ثم سعى "تاريندرا مودي"رئيس الوزراء الهندي إلى بناء سياسة خارجية كجزئه

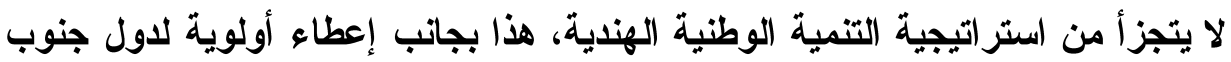

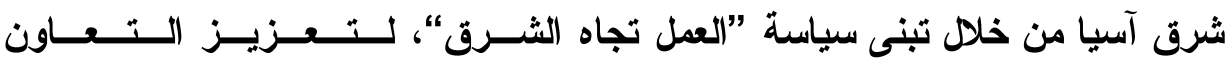

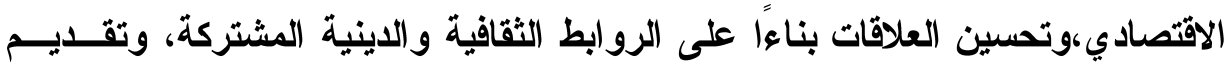

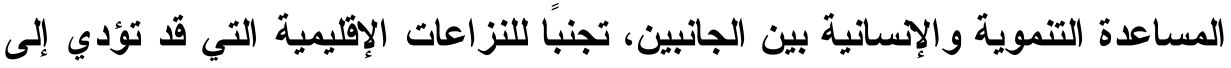

زعزعة الأمن والاستقرار في المنطقة (1)).

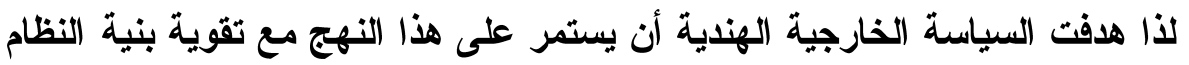

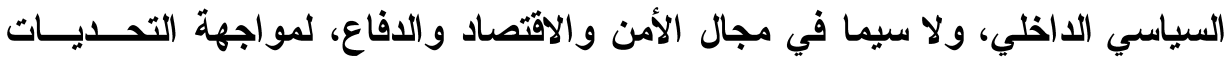

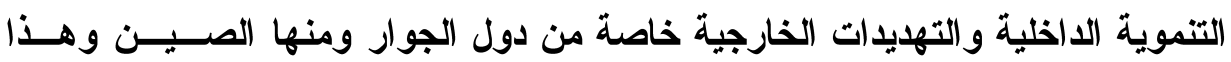
يتضح جليا في مسار التفاعلات الخاصة بمنطقة بحر الصين الجنوبي("آ).

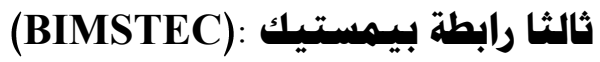
تعرف الرابطة بأنها مبادرة خليج البنغال للتعاون التقني والاقتصادي المتعدد القطاعات

The Bay of Bengal Initiative for Multi-Sectorial Technical and Economic Cooperation

فهي منظمة إقليمية تضم سبع دول أعضاء تقع في المناطق الساحلية و المتاخـــــة

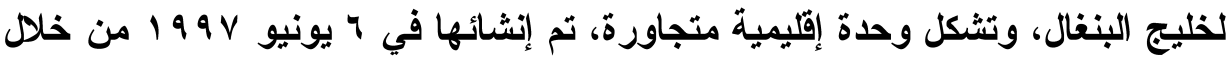

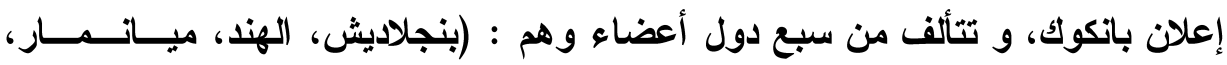
سريلانكا، تايلآد، بوتان، نيبال).

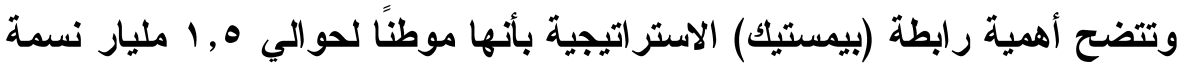

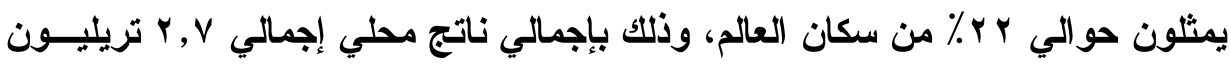

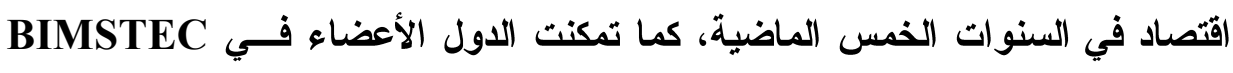




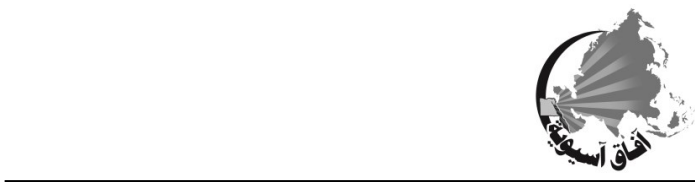

من الحفاظ على مسار نمو اقتصادي متوسط ه, ؟٪ علــى الــرغــم مـن الأوضــاع

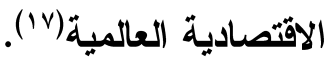

ولقد تم اقرار العديد من التوجيهات بيـن الــدول الأعضــاء Economic and Political integration

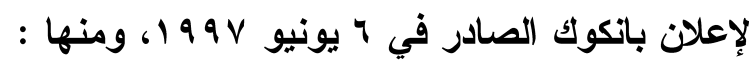

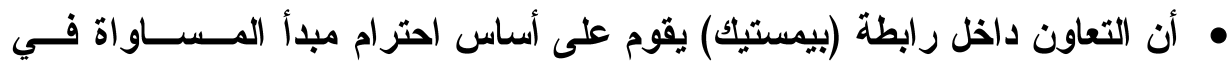

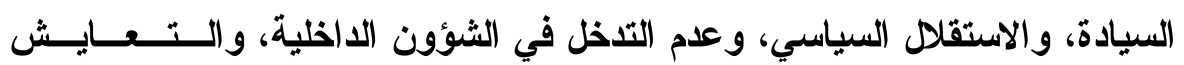

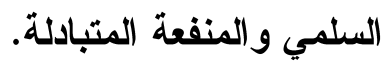
• تهاف الر ابطة الي تدعيم النمو الاقتصادي المشترك من خلادل التعاون المتبادل فئي

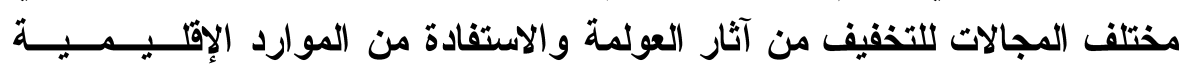
و المزايا الجغر افية للاول الاعضاء يتم عقد الاجتماعات الوزارية السنوية التي تستضيفها الدول الأعضاء على أسـاس الأس التناوب الأبجدي.

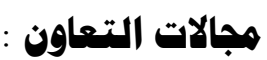

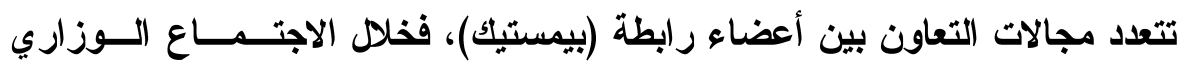

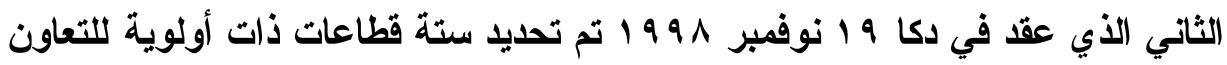

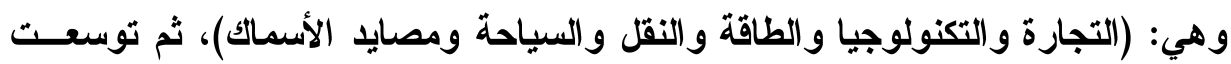

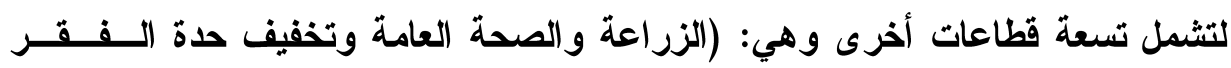
ومكافحة الإرهاب و البيئة و الثقافة، والاتصال r...

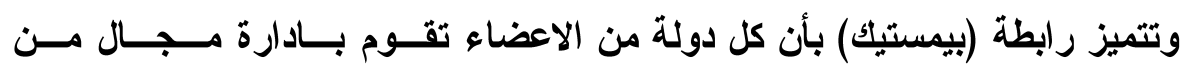

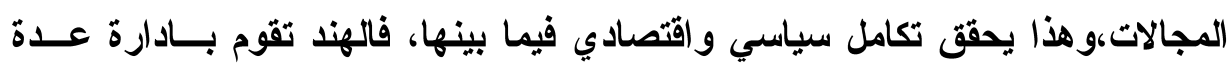

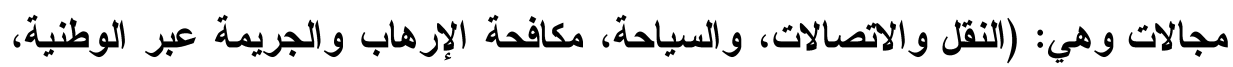

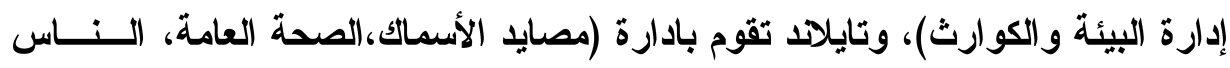

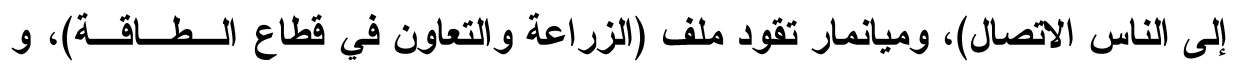




\section{(3)}

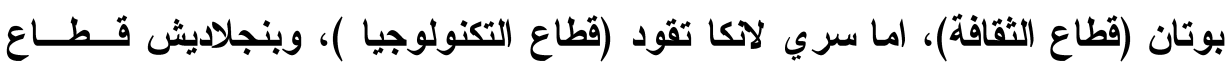

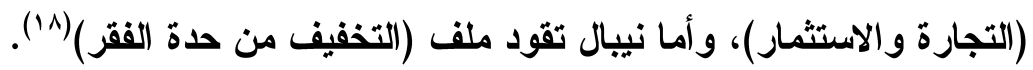

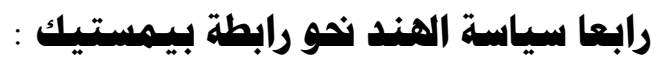

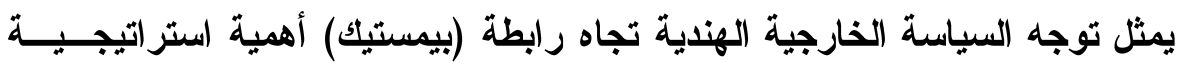

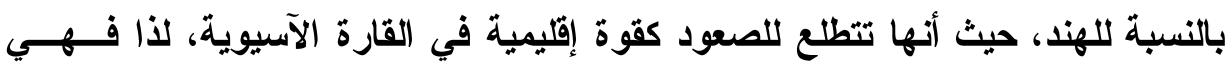

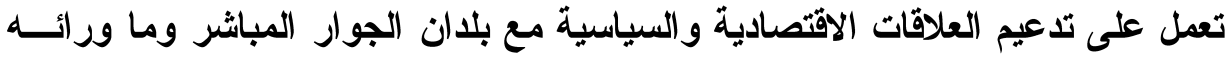

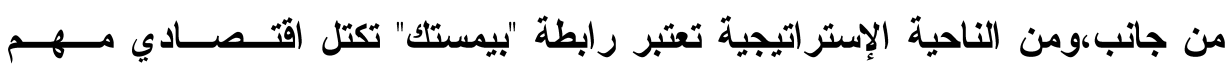

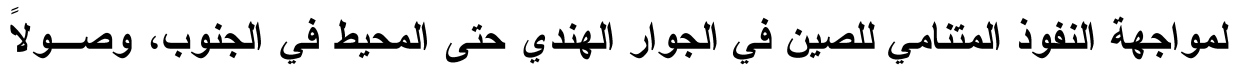
الى نيبال وبوتان الجبلية في الشمال من جاتب آخر.

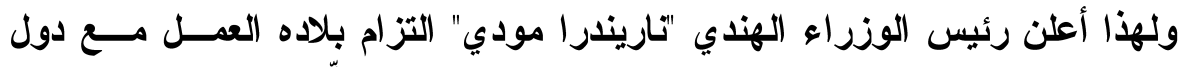

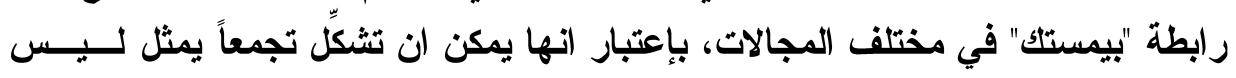

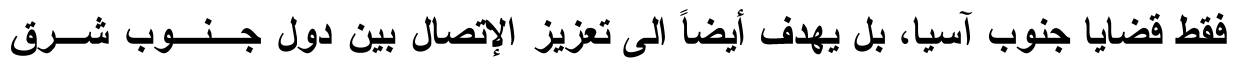

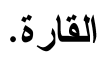

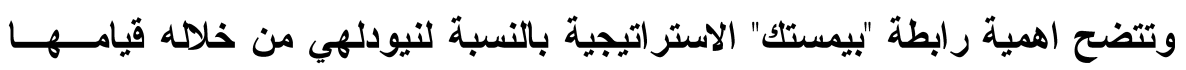

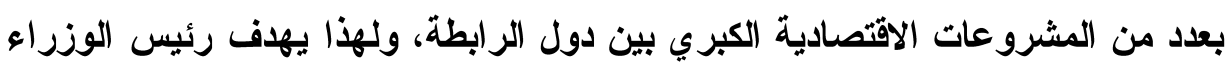

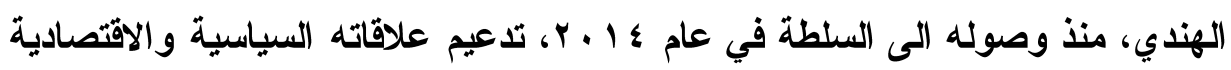

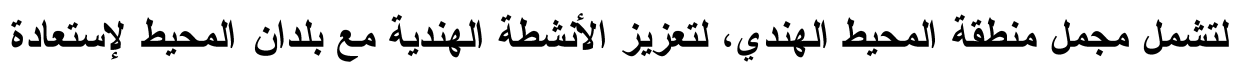

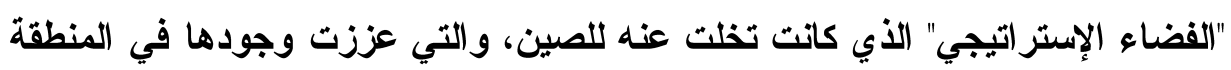

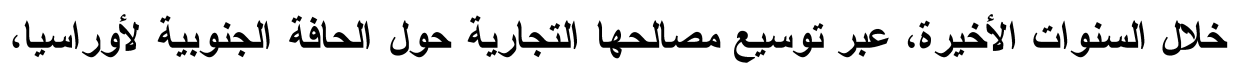

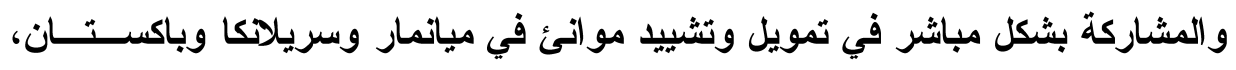

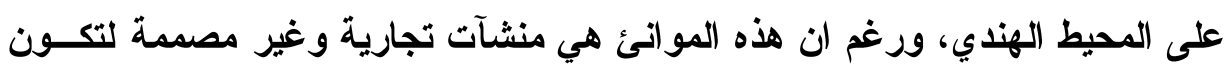

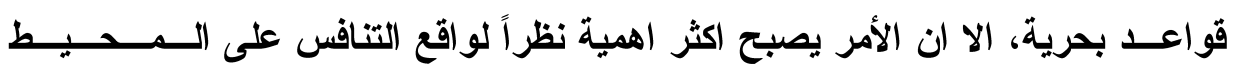

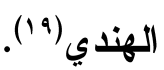

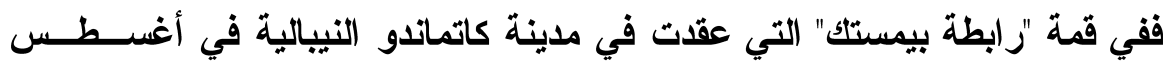

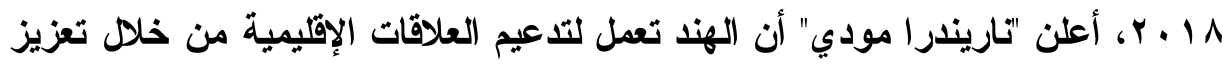

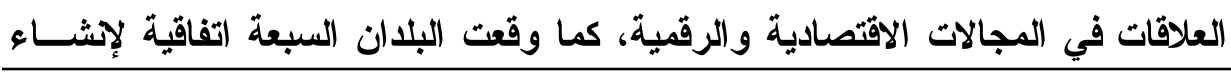

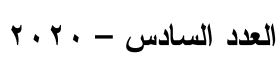




\section{6}

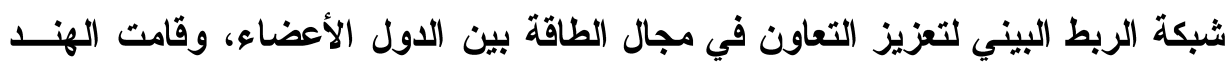

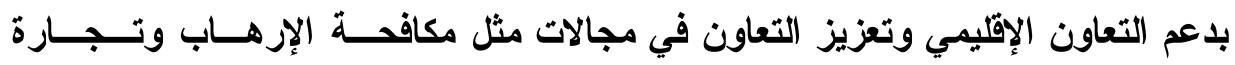

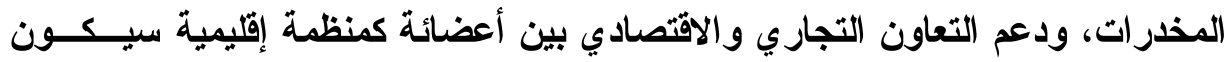
لها ثقل اقتصادي في السنوات المقبلة.

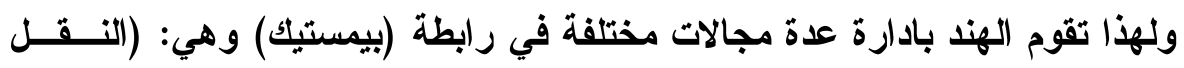

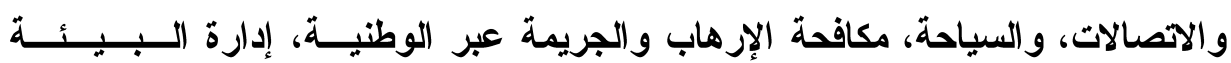

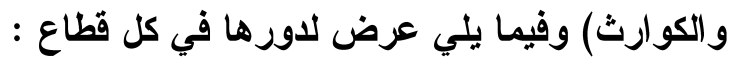

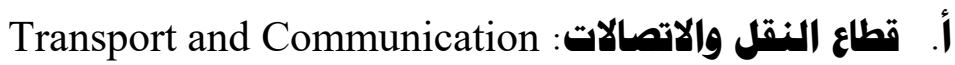

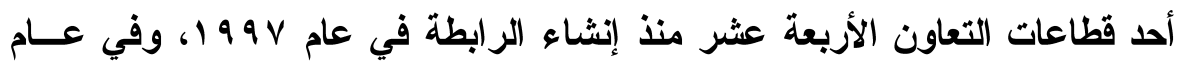

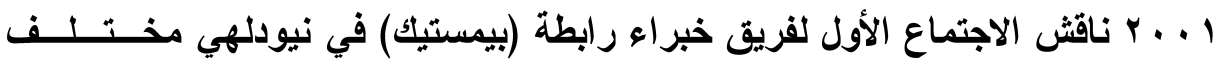

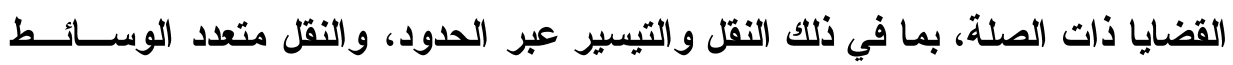

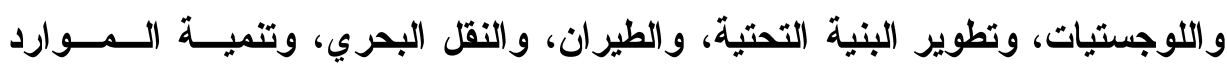
البشرية. وذلك لأهميه إنشاء روابط جوية وبحرية وبرية بين الاول الأبيه العضاء.

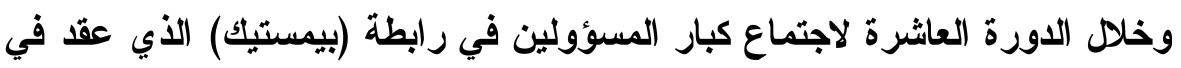

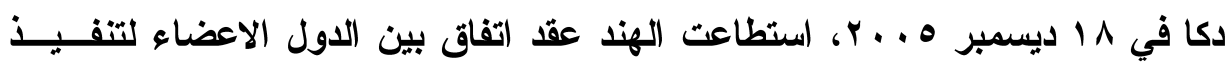
اقتراح بنك التنمية الآسيوي لإجراء دراسة لوجستية النقل بين اعضاء الر ابطة ، ولهنا أجرى بنك التنمية الآسيوي ADB دراسة لاعم النقل والبنية التحتية والتي اكتملت في

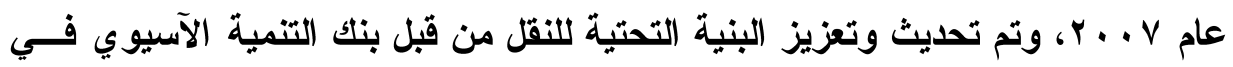

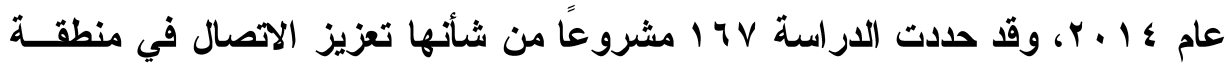

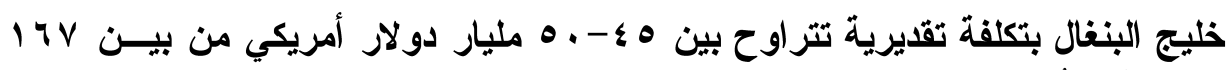
مشروعًا، ليشار إليها باسم مجموعة عمل اتصال النقل (BTCWG)

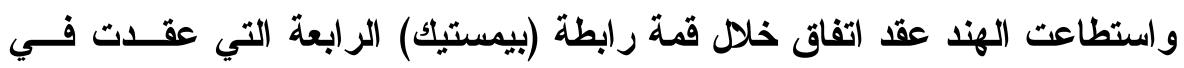

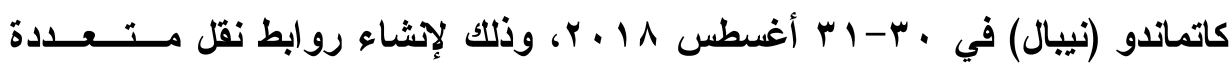

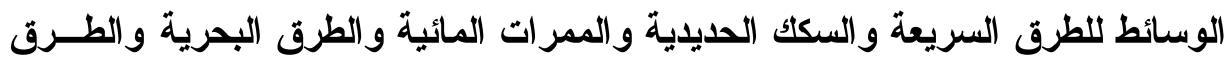

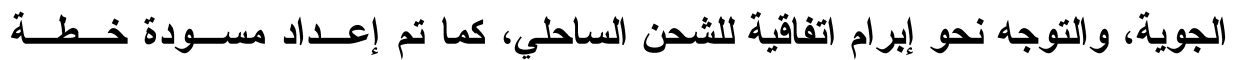

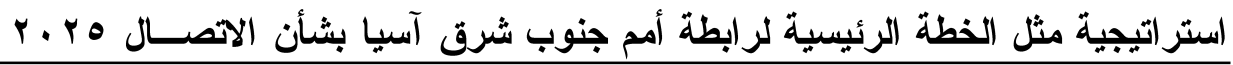

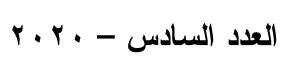




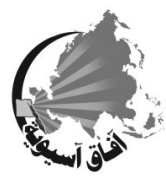

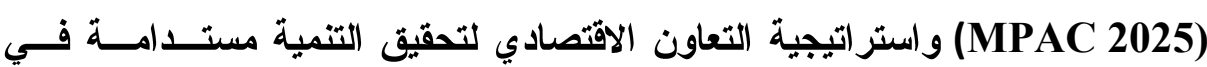

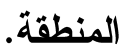

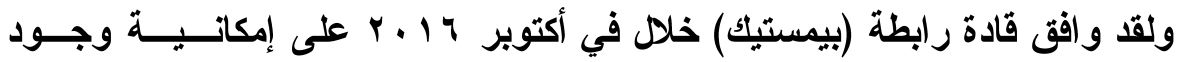

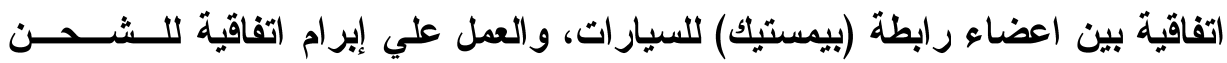

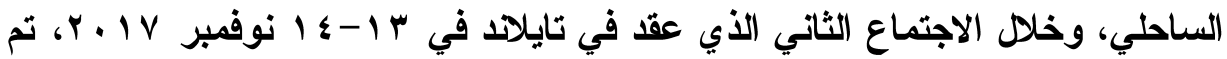

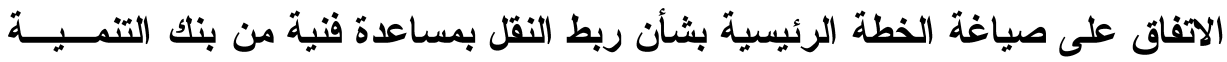

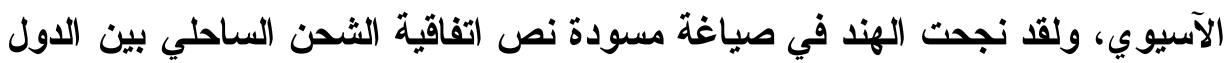

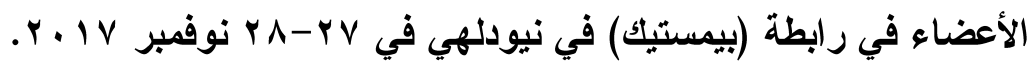

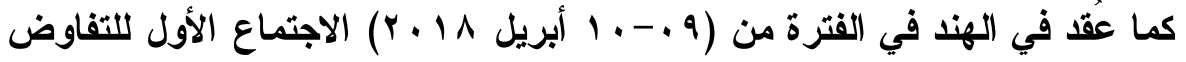

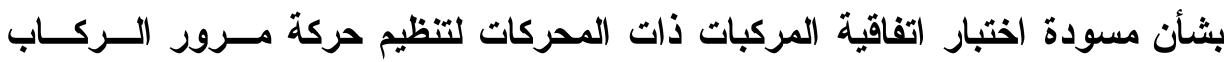
و البضائع بين الدول الأعضاء الرابطة(·r). ب. بطاع السياحة : (Tourism)

استطاعت الهند في الاجتماع الأول لوزراء السياحة التي عقد في كولكاتا بالهند في

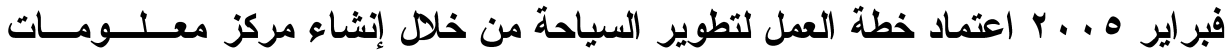

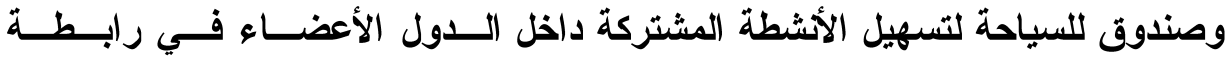
( بيمستيك)، كما نجحت بتأسيس مركز مطلومات في نيودلهي لمتابعة خطة العمل فــي

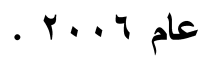

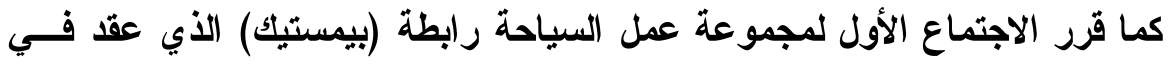

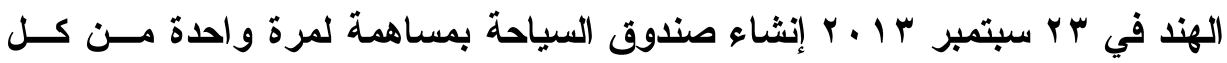

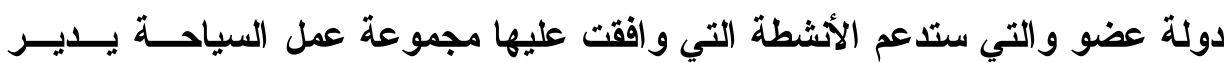
مركز المعلومات صندوق السياحة للرابطة.

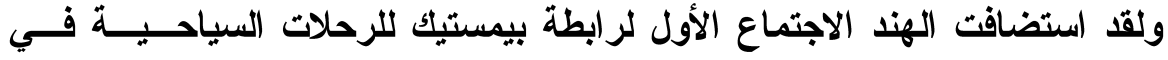

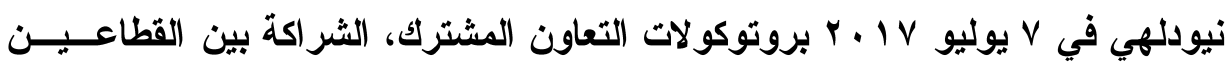

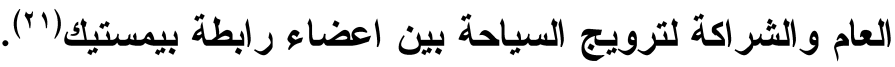




\section{ع. مكافهة الإرهاب والجريمة عبر الوطنية:}

Counter-Terrorism \& Transnational Crime

عند تأسيس رابطة بيمستيك في عام \9 \ 1، دعا قادة الدول الأعضاء إلى التنميــة

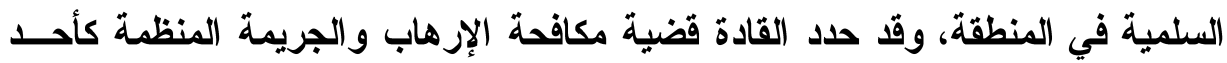

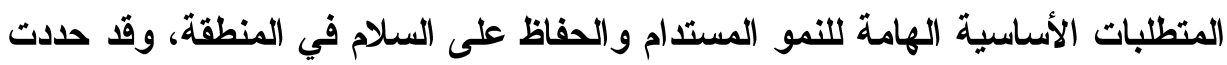

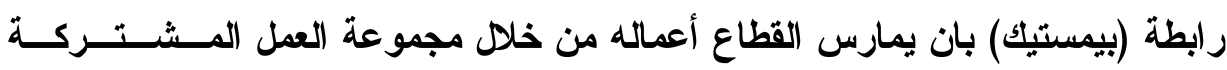

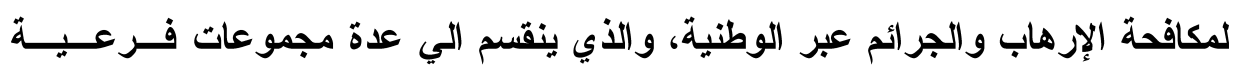

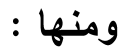

فريق للمخدرات، فريق للاستخبارات، فريق للمسائل القانونية، فريق لمكافحة غسل

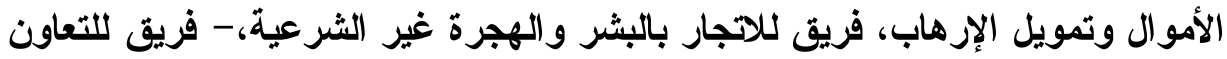

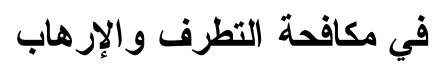

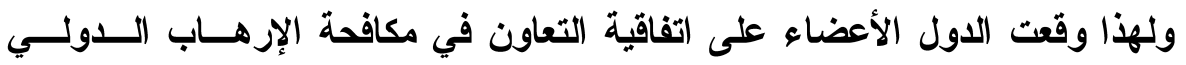

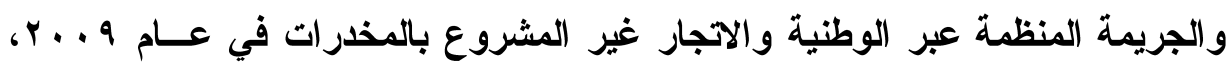

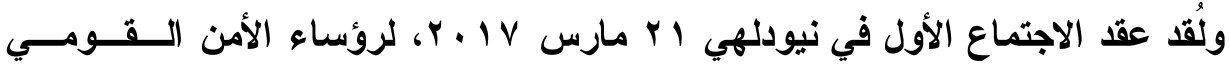

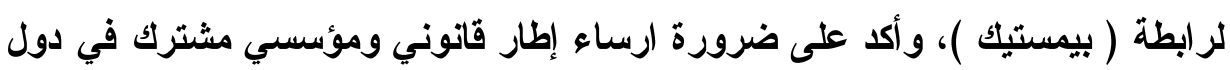

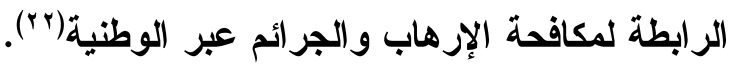

د. إدارة البيئة والكوارث: Environment \& Disaster Management

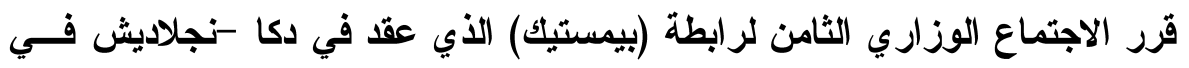

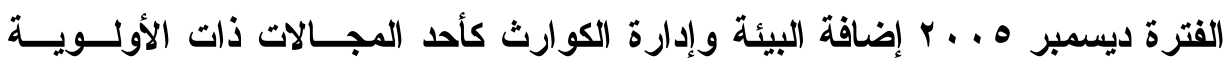

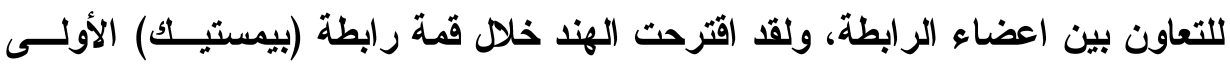

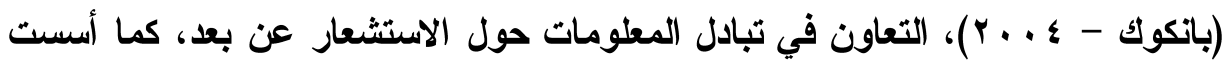

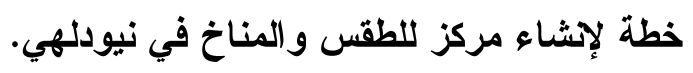

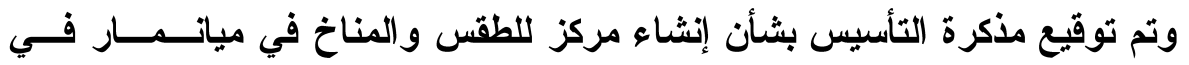

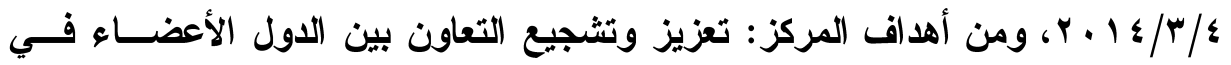

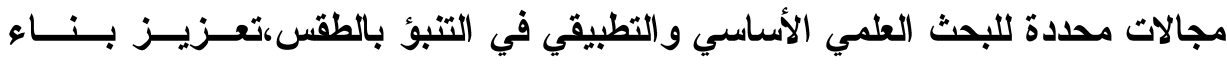

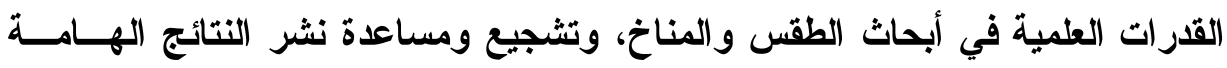




\section{6.}

للبحوث التي تم الحصول عليها في إطار التعاون بشأن الطقس و المناخ.

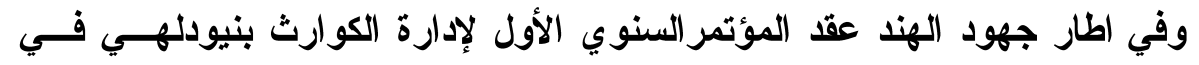

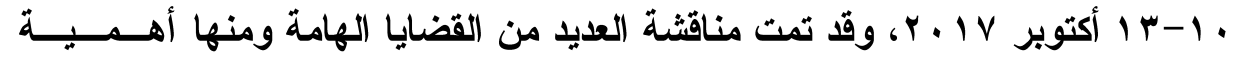

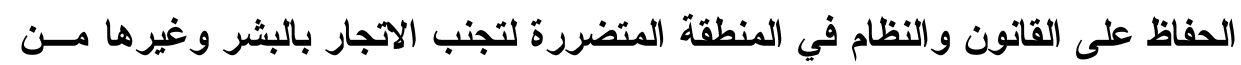

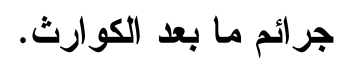

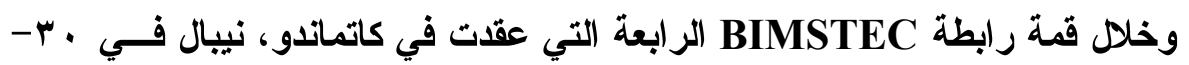

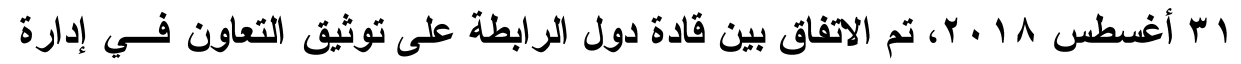

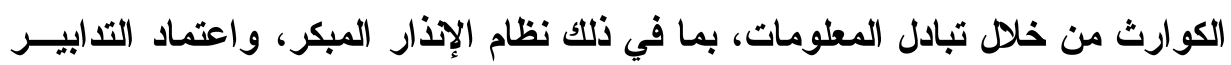

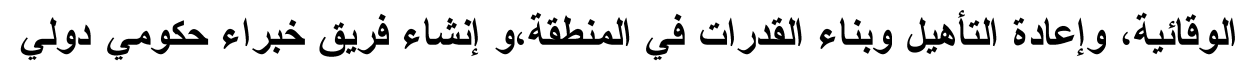

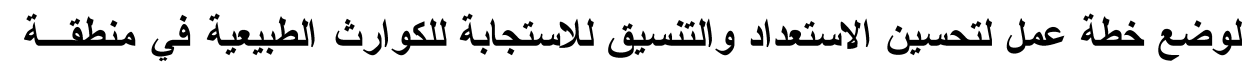

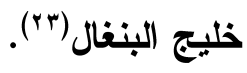

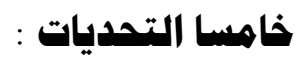

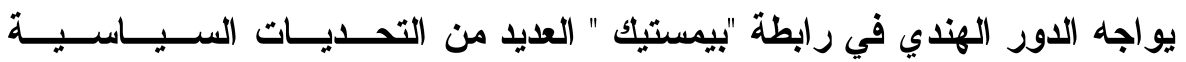

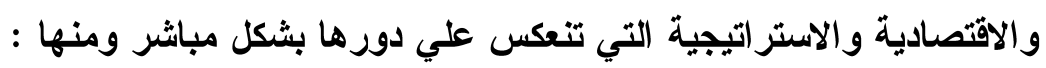

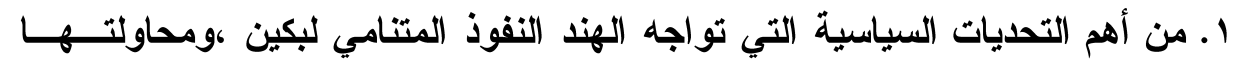

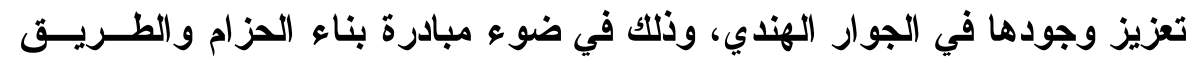
The Belt and Road Initiative (BRI)

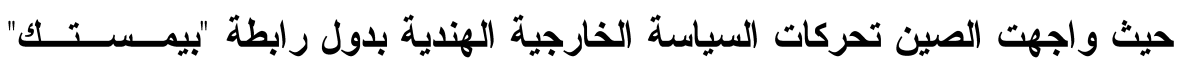

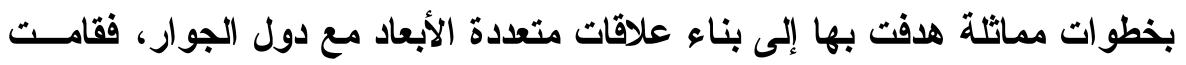

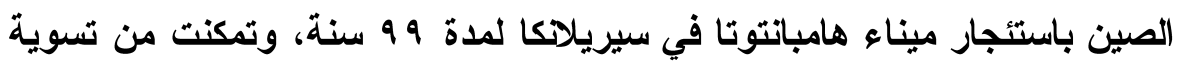

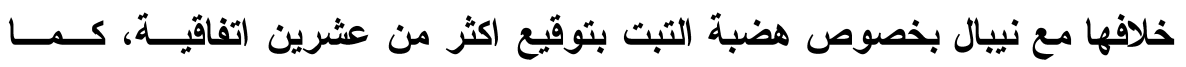

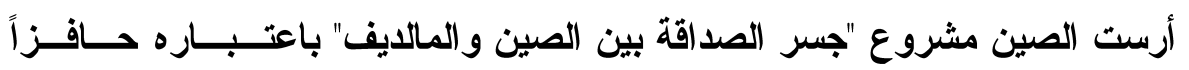

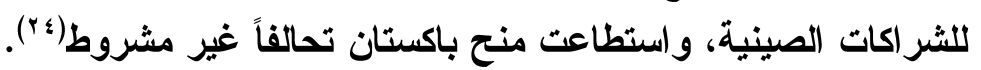

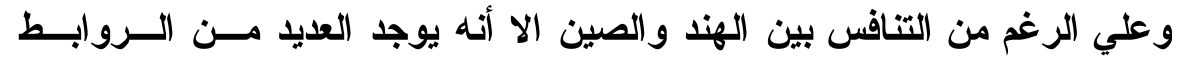

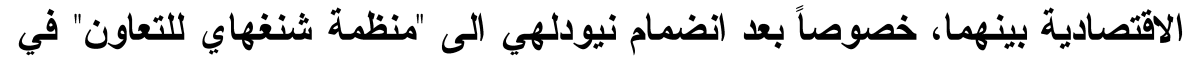

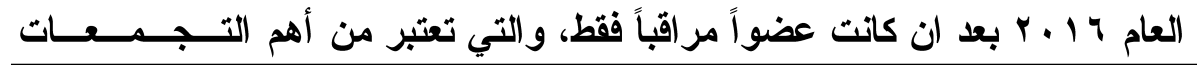

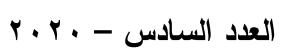
Ir. 


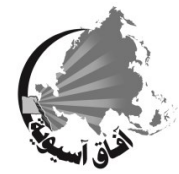

الاقليمية في آسيا، كما أن الدولتين عضوين فاعلين في اتحاد "البريكس"، أبــز

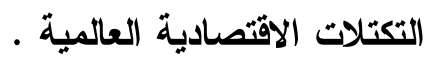

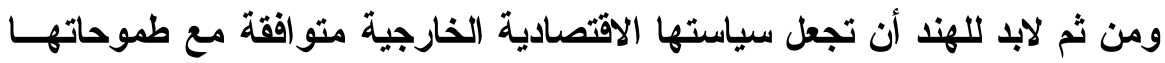

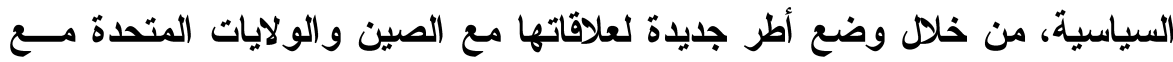

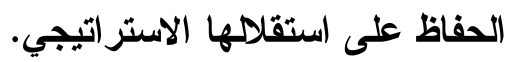

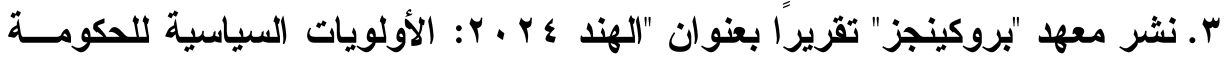

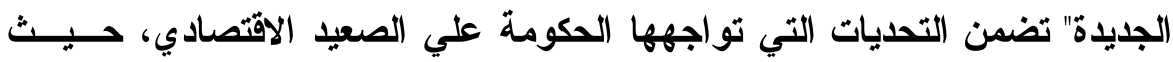

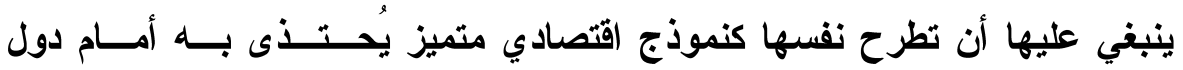

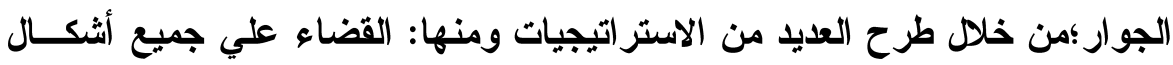

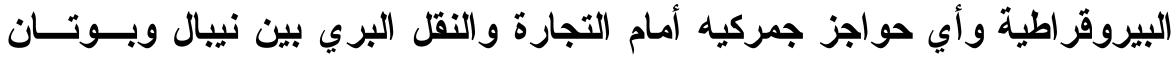

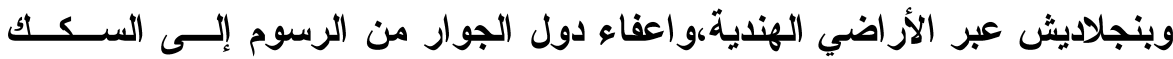

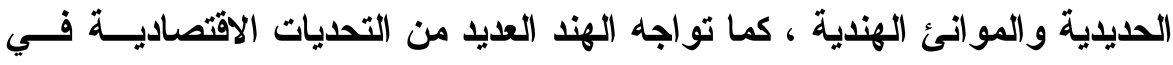

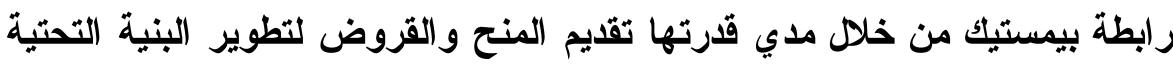

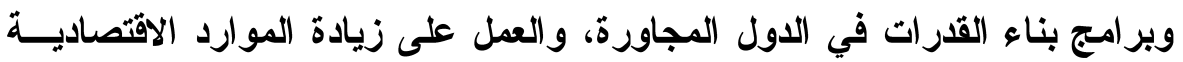

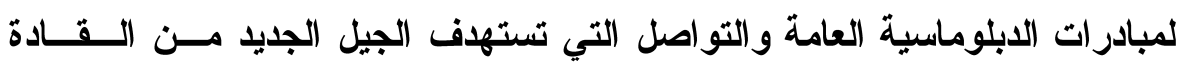

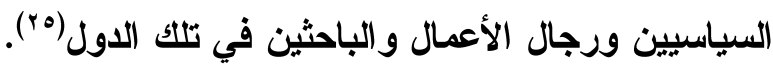

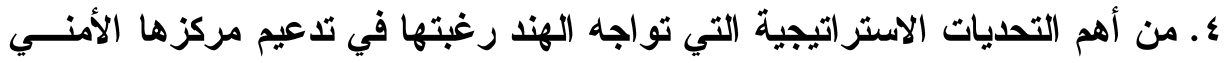

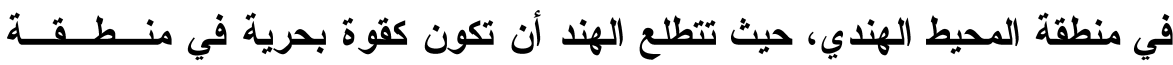

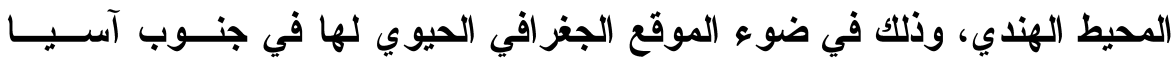

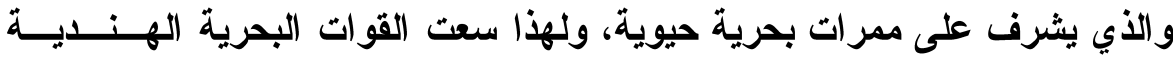

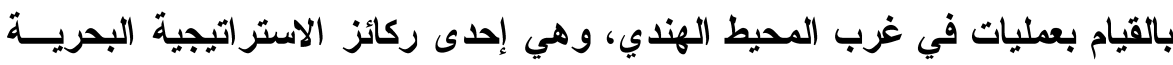

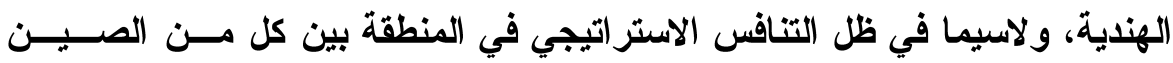

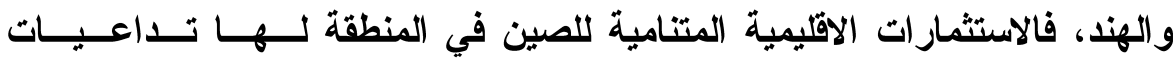

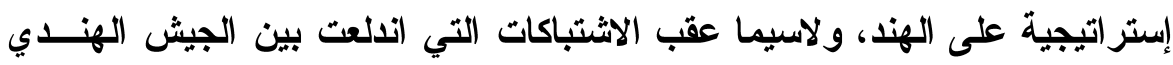

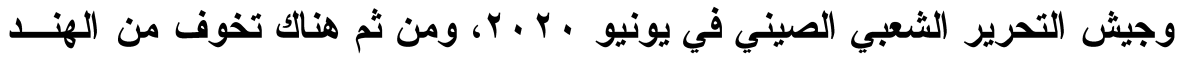

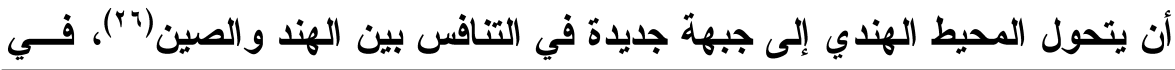




\section{6}

هذه المنطقة التي تعتبر في السابق بمثابة "العمق التقليدي" لها، فضلاً عن الإشغال

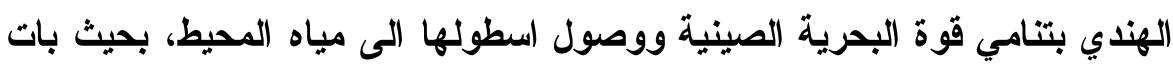

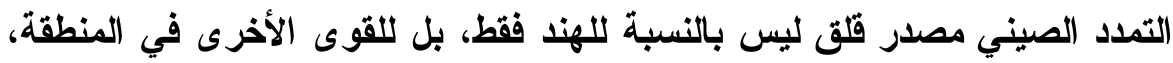

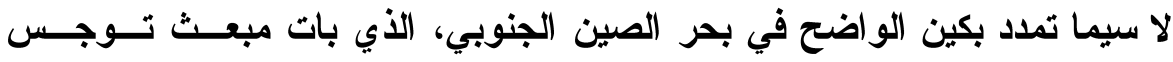

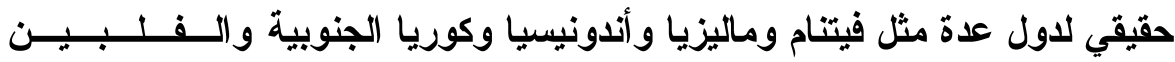

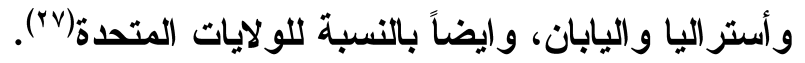

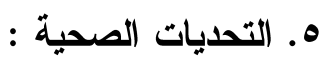

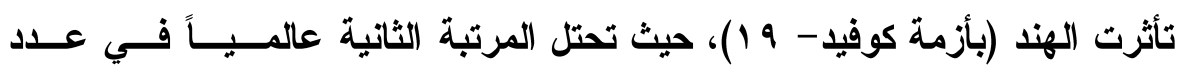

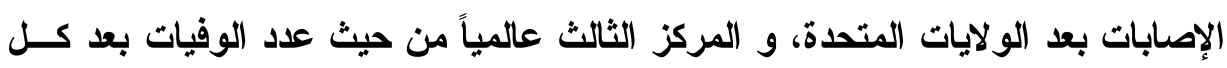

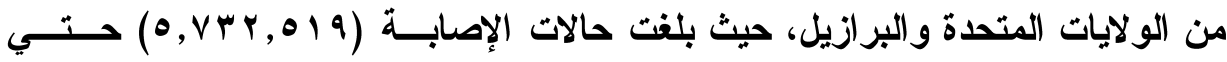

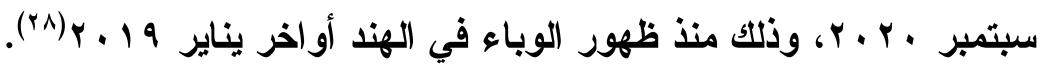

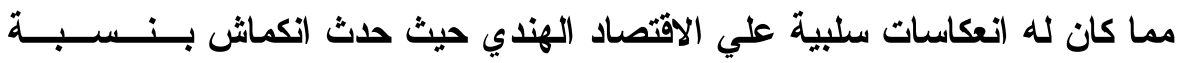

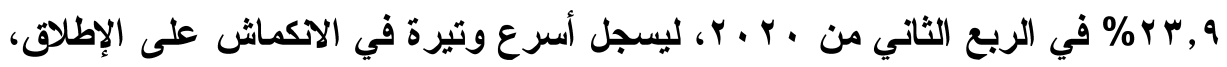

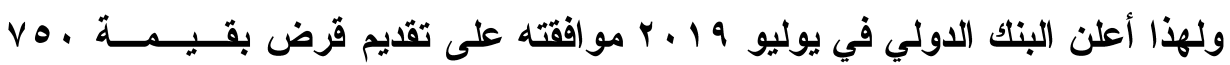

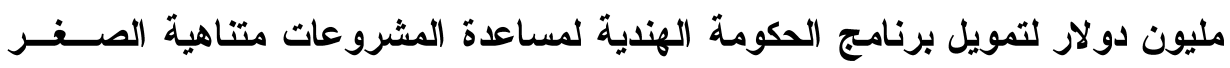

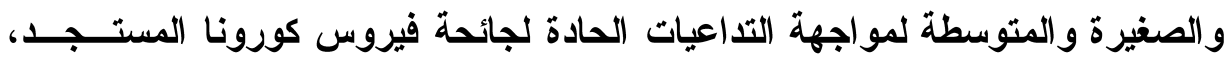

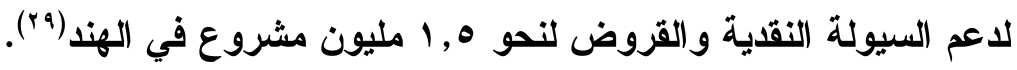

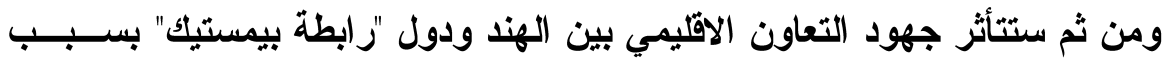

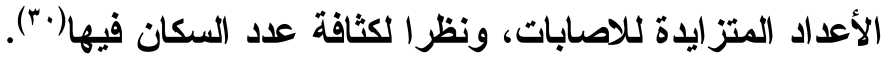
خاتمهة :

تمثل رابطة "بيمستيك" أهمية استر اتيجية بالنسبة للهند، حيث تتطلع الصعود كقـوة

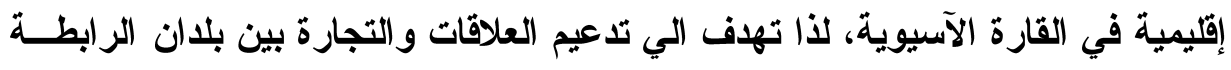

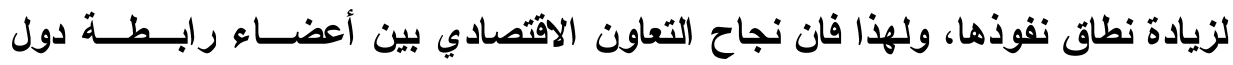

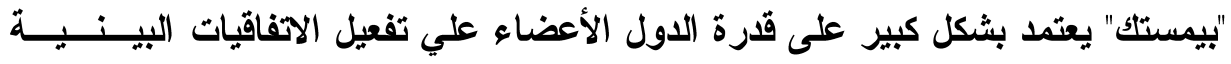

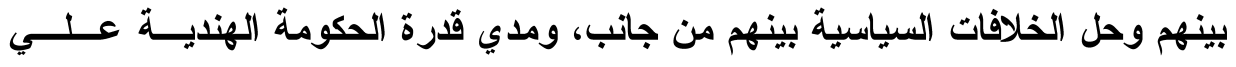
مواجهة التحديات السياسية والاستراتيجية والاثتصادية لتحقيق اهدافها بدعم التعـاون 


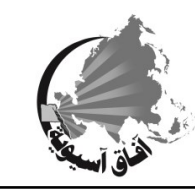

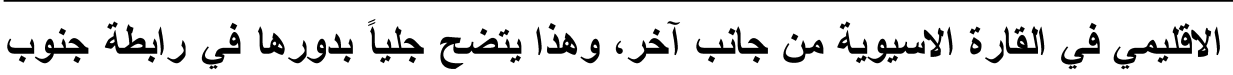

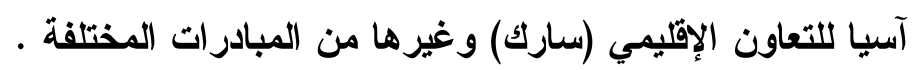

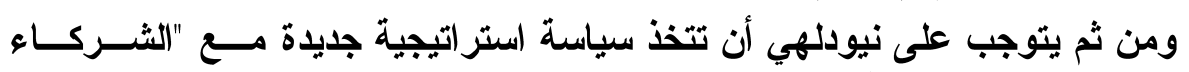

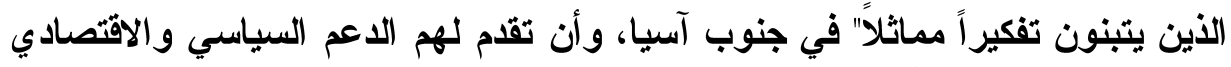

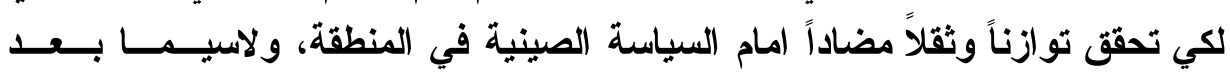

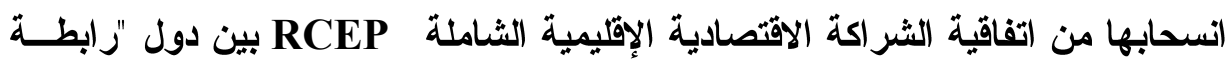

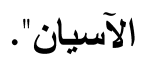




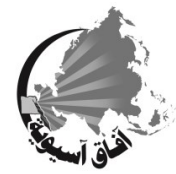

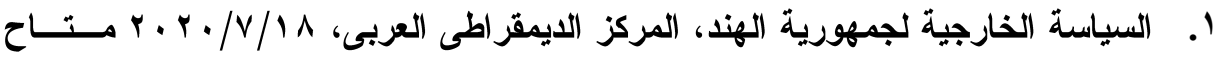

https://democraticac.de/?p= $=7 \vee \wedge \vee \varepsilon$

$$
\text { علي الرابط : }
$$

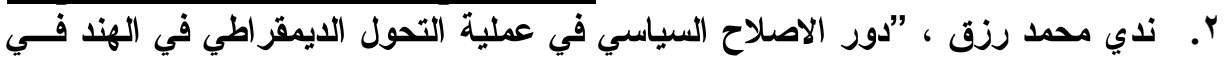

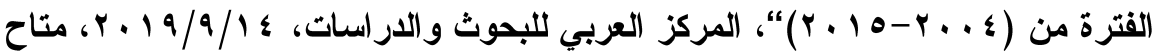

http://www.acrseg.org/\&)

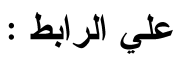

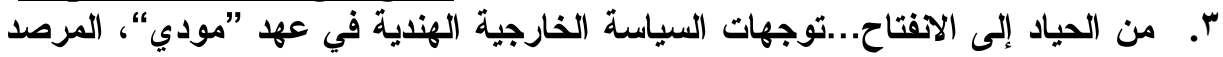

https://marsad.ecsstudies.com/ $v \diamond \vee v$

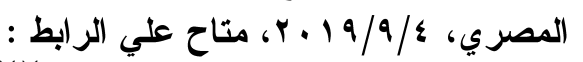

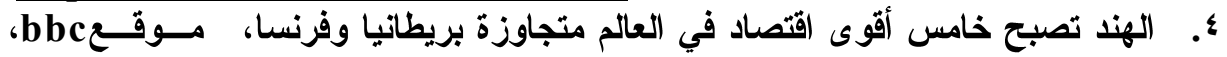

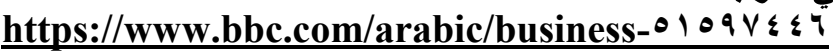

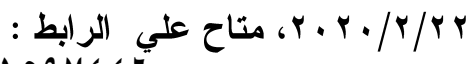

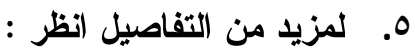

- India: Real gross domestic product (GDP) growth rate from $r$. . 9 to

r. $Y$, , Statista Site, $\theta_{-} \theta_{-}$. $r$. , Available at:

https://www.statista.com/statistics/rqr $\uparrow$ V/gross-domestic-productgdp-growth-rate-in-india

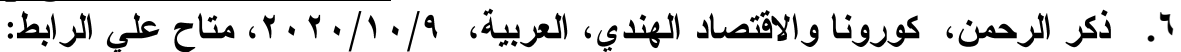

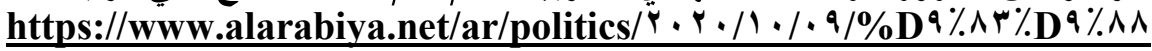

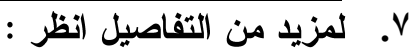

- India: Real gross domestic product (GDP) growth rate from $r$. 9 to r. r , Statista Site, $\theta_{-} \theta_{-} r \cdot r \cdot$, Available at :

https://www.statista.com/statistics/ $/ 4 \% \uparrow \mathrm{V} /$ gross-domestic-product-gdp -growth-rate-in-india

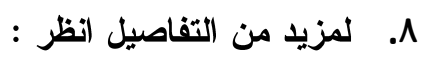

- Jeff Desjardins, "The World's Largest 1. Economies in r.r." , visual capitalist site, January $11, r+19$, Available At :

https://www.visualcapitalist.com/worlds-largest- $1 \cdot$-economies- $r \cdot r$.

9. لمزيد من التفاصيل انظر :

- Jeff Desjardins, "The World's Largest 1. Economies in $r \cdot r \cdot "$, visual capitalist site, January, $\uparrow, 19$, Available At: 11 https://www.visualcapitalist.com/worlds-largest- 1 - -economies- $r \cdot r$.

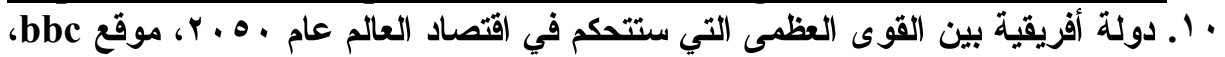

$$
\text { : }
$$

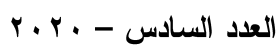




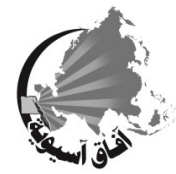

https://Www.bbc.com/arabic/vert-cap- $0 Y .199 Y Y$

11. SUMIT GANGULY," What Is India's Foreign-Policy Vision?, Foreign-Policy, OCTOBER $r^{\top}, r \cdot r \cdot$, Available At:

https://foreignpolicy.com $/ r \cdot r \cdot /, \cdot / \mu / /$ what-is-indias-foreign-policyvision/

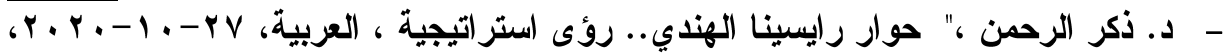

https://www.alarabiya.net/ar/politics/ $r \cdot r \cdot / \cdot 1 / r 7$

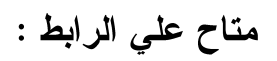

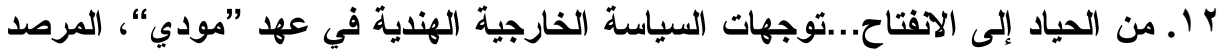

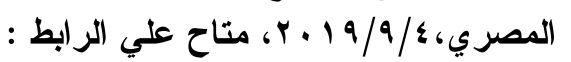

https://marsad.ecsstudies.com/ $\vee$ ○ V

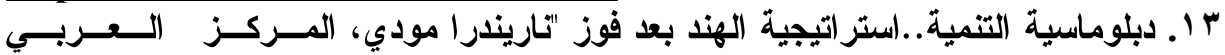

http://www.acrseg.org/\& / $Y$ r $r$

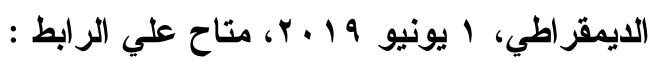

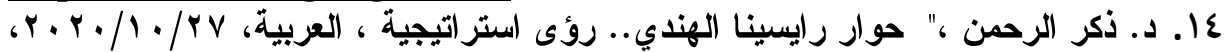

https://www.alarabiya.net/ar/politics/ $r \cdot r \cdot / \cdot 1 / r q$

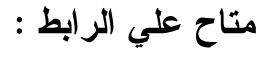

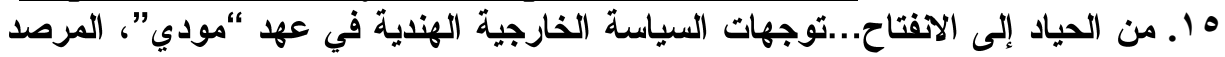

https://marsad.ecsstudies.com/ $\vee$ • v

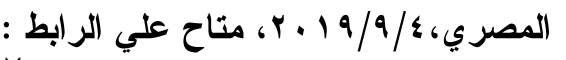

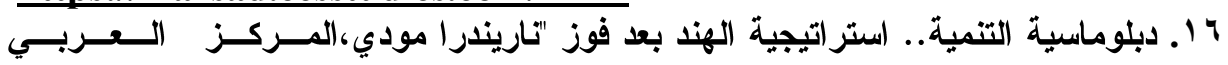

http://www.acrseg.org/\& Irr

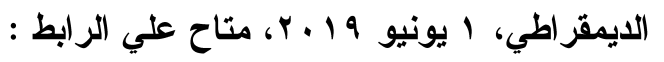

https://bimstec.org/?page $\mathrm{id}=1 \wedge 9$

$$
\text { IV }
$$

18. BIMSTEC Priority Sectors, Areas of Cooperation, Available At:

https://bimstec.org/?page id=199

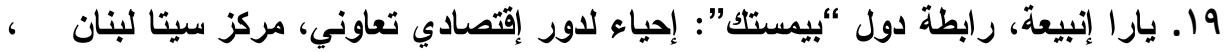

https://sitainstitute.com/?p=r॰1 $r$

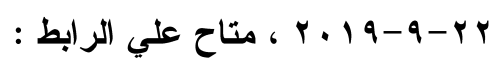

20. Transport and Communication, BIMSTEC Site , $\vee$ July $r+19$,

Available At:

https://bimstec.org/?page $i d=r v$.

21. Tourism, BIMSTEC Site, $r \cdot$ April $r \cdot \mid \Lambda$, Available At:

https://bimstec.org/?page id=r $\vee r$

r. r. - العدد السادس r.

iro 


\section{类}

22. Counter-Terrorism and Transnational Crime, BIMSTEC Site, Available At:

https://bimstec.org/?page $i d=r \wedge$

23. Environment \& Disaster Management, BIMSTEC Sit, Available At:

https://bimstec.org/?page $\mathrm{id}=r \wedge$.

ع ץ. نيها ديوان ، " الهند والصين بين السلام الهش ونقطة اللاعودة" ، مركز تريندز للبحوث

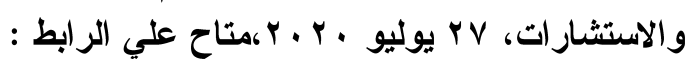

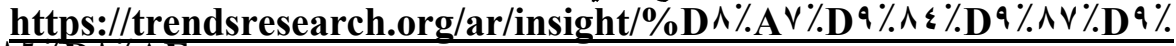

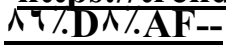

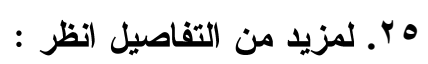

- Dhruva Jaishankar and Zehra Kazmi (editors), India r. r s: Policy Priorities for the new government, Brookings Institution India Center, May r. 19.

ج r. أبهجيت سينج، "تطور الوضع البحري للهند في المحيط الهندي: الفرص المتاحة أمسام

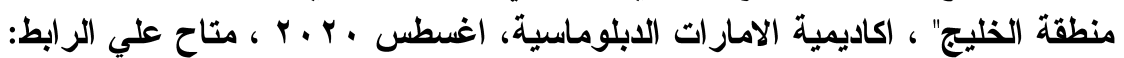
https://eda.ac.ae/docs/default-source/Publications/eda-insight-augI. P.-arb-abhijit.pdf?sfvrsn=气

YV

HTTPS://SITAINSTITUTE.COM/PP=rol

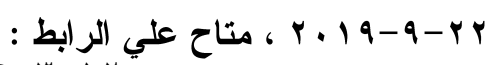

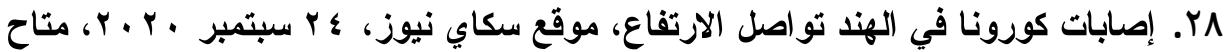

HTTPS://WWW.SKYNEWSARABIA.COM/WORLD/ / ابط /

$$
\text { علي الر ابط : إبطاب }
$$

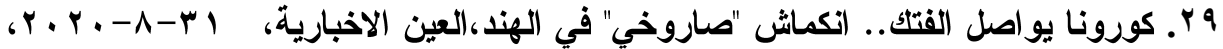

$$
\text { متاح علي الر ابط: }
$$

https://al-ain.com/article/corona-kill-shrinkage-india-fastest-debtbrazil

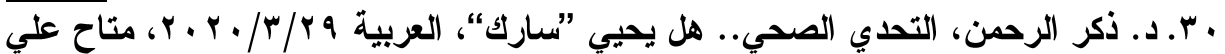

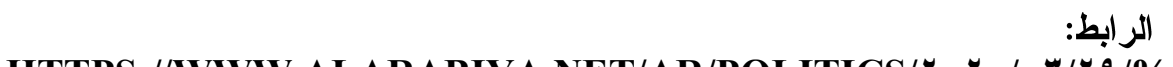

HTTPS://WWW.ALARABIYA.NET/AR/POLITICS/ $/ r \cdot r \cdot r / r q / \%$

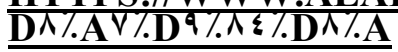

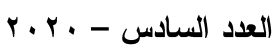

